\title{
HÍBRIDOS DE QUITOSANA-ARGILA PARA ENCAPSULAMENTO E LIBERAÇÃO SUSTENTADA DO FERTILIZANTE NITRATO DE POTÁSSIO
}

\author{
Lucas L. Messa ${ }^{\mathrm{a}}$, José Daniel Froes ${ }^{\mathrm{b}}$, Claudinei F. Souza ${ }^{\mathrm{b}}$ e Roselena Faez $^{\mathrm{a}, *}$ \\ aDepartamento de Ciências da Natureza, Matemática e Educação, Centro de Ciências Agrárias, Universidade Federal de São \\ Carlos, km 174 Araras - SP, Brasil \\ bDepartamento de Recursos Naturais e Proteção Ambiental, Centro de Ciências Agrárias, Universidade Federal de São Carlos, \\ km 174 Araras - SP, Brasil
}

Recebido em 11/05/2016; aceito em 26/05/2016; publicado na web em 20/07/2016

\begin{abstract}
CHITOSAN-CLAY HYBRID FOR ENCAPSULATION OF FERTILIZERS AND RELEASE SUSTAINED OF POTASSIUM NITRATE FERTILIZER. The use of controlled release fertilizers is a trend for improving productivity, reducing costs and environmental pollution. Such materials release gradually the nutrients to the plant in order to supply its requirement and are an alternative to improve fertilization. The preparation of a microsphere from natural materials (chitosan and montmorilonite clay) added with nutrients, according to the needs of plants nutritional, is one of the main motivations of this work. The addition of lamellar silicates as natural clays is a promising alternative to increase water and chemical compounds sorption capacity. In the present chitosan/montmorilonite clay composites were prepared via inversion phase and thermal, structural and morphologically studies were performed. The release of the $\mathrm{KNO}_{3}$ was realized in water using conductimetry and time domain reflectometry technique was used to monitor the in situ release in soil. Double coated microspheres provide the better nutrient encapsulation and a swelling of $200 \%$ was observed. The release was influenced by $\mathrm{pH}$ and fast release was observed for $\mathrm{pH} 4$ and 5.5. According to the soil tests a slow release was observed since the $\mathrm{KNO}_{3}$ delivery was accompanied during 60 days showing higher values in the first ten days and a constant value until 60 days.
\end{abstract}

Keywords: Controlled ferti-release; nutrient; agricultural practices; TDR technique.

\section{INTRODUÇÃO}

O Brasil é considerado um dos maiores importadores de fertilizantes no mundo e o quarto maior consumidor, ficando atrás apenas da China, da Índia e dos Estados Unidos. ${ }^{1}$ Essa grande importação e consumo de adubos na agricultura brasileira podem ser justificadas por diversos fatores, tais como: grande área de cultivo no país que indica a enorme produção agrícola; características dos solos, pobres em nutrientes como potássio e fósforo; e produção insuficiente de adubos potássicos, fosfatados e, principalmente, nitrogenados. ${ }^{2}$ Fertilizantes industriais têm sido largamente empregados nas áreas agrícolas para a adubação do solo. No entanto, a utilização incorreta desses insumos pode causar tanto impactos ambientais quanto econômicos. No ambiente, pode ser responsável pela poluição de lençóis freáticos e águas de rios devido à erosão, acidificação e emissão de gases de efeito estufa como o óxido nitroso $\left(\mathrm{N}_{2} \mathrm{O}\right)$, principalmente pelo uso de adubos de origem nitrogenada. Os impactos econômicos são decorrentes das despesas de aquisição de fertilizantes, muitos importados, que representam grande parte dos custos de produção de alimentos. ${ }^{3}$ Assim, é necessário procurar métodos alternativos para manejo de nutrientes ao solo. O uso de fertilizantes em liberação controlada na agricultura tem sido utilizado de modo crescente nos últimos anos, sendo considerada uma alternativa promissora para melhorar inúmeros aspectos de fertilização com base no conceito de liberação controlada. ${ }^{4}$ A utilização de insumos agrícolas em liberação controlada tem aumentado devido à necessidade de reforçar os sistemas de produção com o aumento da produtividade e redução de custos. Adicionalmente, estes materiais podem ser utilizados como condicionadores do solo uma vez que melhoram a disponibilidade de água. ${ }^{5,6}$ As principais vantagens do seu uso são: o fornecimento

*e-mail: faez@cca.ufscar.br regular e contínuo de nutrientes para as plantas; menor frequência de aplicações em solos; redução de perdas de nutrientes devido à lixiviação, imobilização e volatilização; eliminação de danos causados a raízes pela alta concentração de sais; maior praticidade no manuseio dos fertilizantes: contribuição à redução da poluição ambiental pelo $\mathrm{NO}_{3}{ }^{-}$; atribuição de valor ecológico à atividade agrícola (menor contaminação de águas subterrâneas e superficiais); redução de custos de produção. ${ }^{7}$ A quitosana tem sido amplamente explorada como um material de revestimento para a preparação de materiais de liberação controlada por um sistema em que as taxas de dissolução e de liberação dependem diretamente das características do material. ${ }^{8}$ A quitosana é um copolímero de 2-amino-2-deoxi-D-glicopiranose e 2-acetamido-2-deoxi-D-glicopiranose de composição variável em função do grau médio de acetilação. ${ }^{9}$ Este biopolímero é obtido a partir da desacetilação parcial da quitina, que é um polissacarídeo encontrado abundantemente na natureza e principal componente do exoesqueleto de insetos e crustáceos. ${ }^{10}$ Em relação a sua estrutura química, possui grupos amina $\left(\mathrm{NH}_{2}\right)$ e hidroxila $\left(\mathrm{OH}^{-}\right)$capazes de interagir com distintas moléculas e/ou íons. É solúvel em alguns ácidos diluídos formando um polímero catiônico com a protonação do grupo amino $\left(\mathrm{NH}_{3}{ }^{+}\right)$, que lhe confere propriedades interessantes como biocompatibilidade, biodegradabilidade e não toxicidade, aliadas à capacidade de formar fibras, filmes, géis e microesferas, responsáveis por suas mais diversas aplicações. ${ }^{11,12}$

Além disso, a combinação de materiais inorgânicos e polímeros tem sido uma estratégia de sucesso no desenvolvimento de novas propriedades, chamando a atenção nos últimos anos, devido à obtenção de materiais com propriedades novas ou melhores do que o polímero puro. A adição de silicatos lamelares, tais como argila montmorilonita, é uma alternativa promissora para melhorar certas propriedades, ou seja, aumentar a capacidade de sorção para ambos os compostos químicos e de água. ${ }^{13} \mathrm{Na}$ literatura, diferentes métodos 
descrevendo o processo de preparação de microesferas de quitosana têm sido publicados, tais como atomização, ${ }^{14}$ gelificação ionotrópica $^{15}$ e inversão de fase. ${ }^{6,10}$ Neste último método, a formação de microesferas se dá pela neutralização da solução ácida de quitosana por uma base forte, tipicamente hidróxido de sódio. Esta solução coagula a quitosana no formato de gotas que ficam em suspensão na solução coagulante com ajuda de uma agitação mecânica lenta. ${ }^{10}$ Com base no que foi exposto, este trabalho teve como objetivo congregar as propriedades de materiais de origem natural (quitosana e argila montmorilonita) na obtenção de um material híbrido na forma de microesfera para encapsulamento e liberação controlada de fertilizantes. As microesferas de quitosana-argila foram preparadas com dupla camada pelo método de inversão de fase baseado no trabalho de Santos. ${ }^{6} \mathrm{O}$ fertilizante comercial nitrato de potássio $\left(\mathrm{KNO}_{3}\right)$ foi testado como nutriente devido ao fato de este composto apresentar grande mobilidade no solo. A motivação principal está na preparação de uma microesfera a partir de materiais naturais (quitosana e argila montmorilonita) aditada com nutrientes e a sua aplicação no solo com acompanhamento in situ da liberação do nutriente por uma técnica eletromagnética que avalia a movimentação iônica em sistemas particulados, como é o caso do solo. O aumento da eficiência do uso do fertilizante, a redução da toxicidade no solo e a diminuição dos efeitos negativos associados à sobredosagem são algumas das vantagens de materiais de liberação controlada. Vale ressaltar que a sinergia das propriedades dos materiais quitosana/ argila alia as propriedades de biopolímeros e cargas naturais com a sustentabilidade do seu uso no solo em função das propriedades biodegradáveis da quitosana. ${ }^{13}$

\section{PARTE EXPERIMENTAL}

\section{Materiais}

Os reagentes Quitosana (Polymar S/A, grau de desacetilação $85 \%$ e massa molar $1,8 \times 10^{-5} \mathrm{~g} \mathrm{~mol}^{-1}$ ), Ácido Acético Glacial (Synth, P.A.), Ácido Bórico (Sigma-Aldrich, P.A.), Acetato de Sódio (Synth, P.A.), Cloreto de Potássio (Êxodo Científica, P.A.), Hidróxido de Sódio Micropérola (Synth, P.A.), Argila Montmorilonita Brasgel Aço A (concedida pela Bentonit União, CTC $85 \mathrm{mmol} / 100 \mathrm{~g}$ de argila), Nitrato de Potássio (concedido pelo Laboratório de Solos - UFSCar Centro de Ciências Agrárias) foram utilizados sem prévia purificação.

\section{Preparação de argila-nutriente}

O nitrato de potássio foi adicionado à argila na proporção de argila: fertilizante $1: 3(\mathrm{~m} / \mathrm{m})$, considerando a capacidade de troca catiônica da argila. A mistura foi realizada pelo processo mecanoquímico em que o nutriente foi adicionado à argila por maceração em almofariz previamente à mistura com a quitosana e preparação das microesferas. A mistura foi macerada durante 10 minutos e, após este período, foi levada à estufa para secar a temperatura controlada de $100{ }^{\circ} \mathrm{C}$.

\section{Preparação de microesferas ferti-liberadoras}

Inicialmente, foram preparadas duas soluções de quitosana de concentrações de 2 e $5 \%(\mathrm{~m} / \mathrm{v})$. Para isso, a quitosana em pó foi solubilizada em uma solução aquosa de ácido acético $5 \%$ (v/v), permanecendo sob agitação por 24 horas. Após total solubilização, as dispersões apresentaram-se com coloração marrom (claro), transparente e sem a presença de grumos. $\mathrm{O} \mathrm{pH}$ das soluções de quitosana de 2 e $5 \%(\mathrm{~m} / \mathrm{v})$ foram 3,2 e 3,6, respectivamente.

Para a preparação das microesferas de camada dupla (QAFmcd), partículas de quitosana-argila-fertilizante (QAFp) foram preparadas em uma etapa intermediária à preparação das microesferas. Inicialmente, $50 \mathrm{~mL}$ da solução de quitosana $2 \%(\mathrm{~m} / \mathrm{v})$ e $7 \mathrm{~g}$ de argila-nutriente foram misturados por agitação mecânica durante 24 horas. Após o processo de agitação, foi obtido um filme por evaporação da mistura (quitosana-argila-fertilizante), o qual foi triturado para obtenção de partículas. Após, as partículas foram adicionadas a $50 \mathrm{~mL}$ de solução de quitosana $5 \%(\mathrm{~m} / \mathrm{v})$. A solução assim obtida foi gotejada sobre uma solução de hidróxido de sódio $8 \%(\mathrm{~m} / \mathrm{v})$ sob agitação magnética, produzindo as microesferas de camada dupla. As microesferas foram lavadas com água destilada até atingir $\mathrm{pH} 7,5$. Por fim, as microesferas úmidas foram levadas à estufa para secar a temperatura controlada de $100{ }^{\circ} \mathrm{C}$. A Figura 1 mostra um fluxograma do processo de preparação das microesferas de camada dupla. A fim de comparação, microesferas de camada simples (QAFmcs) foram obtidas pela homogeneização em agitação mecânica de $7 \mathrm{~g}$ de argila-nutriente e $70 \mathrm{~mL}$ de solução de quitosana $5 \%(\mathrm{~m} / \mathrm{v})$. A solução obtida foi gotejada sobre uma solução de hidróxido de sódio $8 \%(\mathrm{~m} / \mathrm{v})$ sob agitação magnética. Após, as microesferas foram lavadas e secas em estufas. A Tabela 1 mostra a composição teórica e experimental dos materiais.

\section{Caracterização estrutural, morfológica e composição química dos materiais}

Espectros de infravermelho por transformada de Fourier (FTIR) foram registrados varrendo a região do espectro eletromagnético entre 4000 a $400 \mathrm{~cm}^{-1}$, usando um Espectrômetro Bomem, modelo MB100 equipado com detector DGTS e técnica de pastilha em $\mathrm{KBr}$

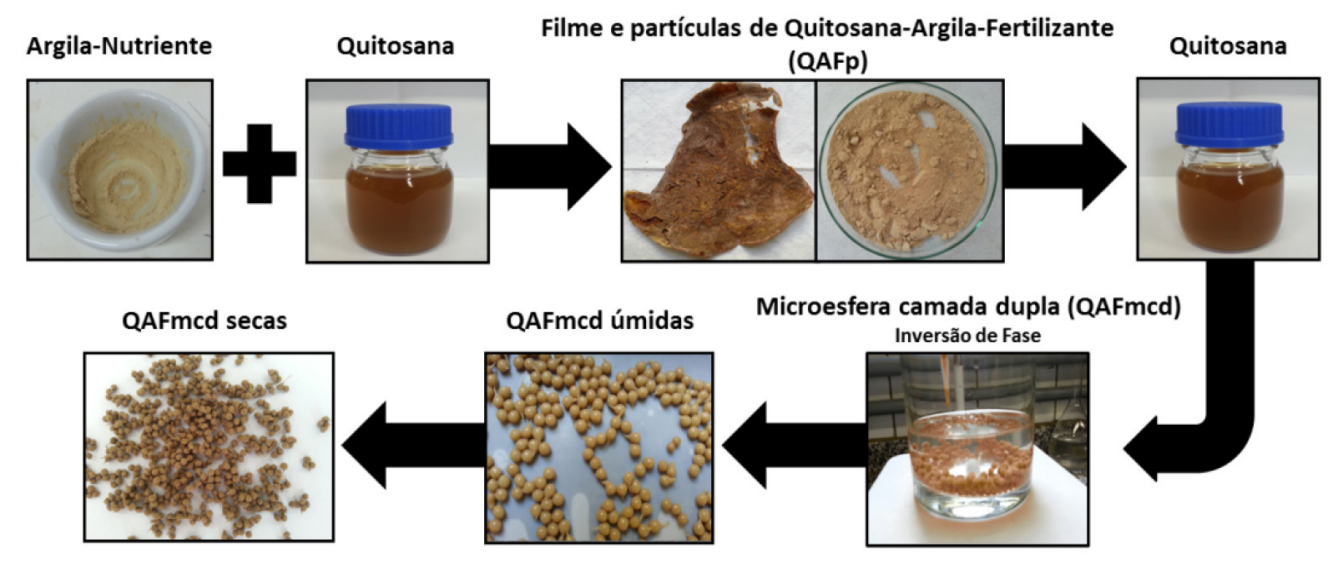

Figura 1. Processos de preparação das microesferas ferti-liberadoras 
Tabela 1. Composição química teórica $(\mathrm{T})$ e experimental* $(\operatorname{Exp})$ dos materiais

\begin{tabular}{|c|c|c|c|c|c|c|}
\hline \multirow[t]{2}{*}{ Material } & \multicolumn{2}{|c|}{ Quitosana (\%) } & \multicolumn{2}{|c|}{ Argila (\%) } & \multicolumn{2}{|c|}{ Fertilizante $(\%)$} \\
\hline & $\mathrm{T}$ & Exp & $\mathrm{T}$ & Exp & $\mathrm{T}$ & Exp \\
\hline Argila-nutriente & ---- & --- & 25 & 28 & 75 & 72 \\
\hline Partículas (QAFp) & 16 & 18 & 21 & 23 & 63 & 59 \\
\hline Microesferas (QAFmcd) & 33 & 45 & 17 & 23 & 50 & 32 \\
\hline
\end{tabular}

*O teor experimental foi obtido a partir das curvas TG.

para sólidos. Ensaios de difração de raios-X (DRX) foram realizados em um difratômetro D8 Discover em configuração padrão OP1: passo $0,02, \mathrm{t}=6 \mathrm{~s}, 10 \mathrm{rpm}$, twin primária $0,6 \mathrm{~mm}=0,3^{\circ}$, soller axial primária, twin secundária aberta fixa $5 \mathrm{~mm}=2,5^{\circ}$, soller axial secundária, filtro de níquel, detector modo ID aberto $2,94^{\circ}$, com feixe de cobre e configuração $40 \mathrm{kV}, 30 \mathrm{~mA}$, monitorando os ângulos de difração 2 theta $(2 \theta)$ de 0 a $30^{\circ}$, sobre amostra na forma de pó. Imagens de microscopia eletrônica de varredura (MEV) das microesferas foram registradas em um microscópio eletrônico modelo HITACHI TM3000, com tensão de aceleração de 15 kV, fonte de tungstênio. Análises de espectroscopia de absorção atômica foram realizadas por um espectrômetro de absorção atômica Varian AA240FS Fast Sequential AAS para determinar os teores dos macronutrientes. A abertura da amostra foi feita com digestão nítrico-perclórico (razão 3:1), visando solubilizar totalmente a amostra sólida. A estabilidade térmica das amostras foi determinada por análise termogravimétrica, sendo as amostras aquecidas à taxa de $10^{\circ} /$ minuto de 25 a $1100{ }^{\circ} \mathrm{C}$, sob atmosfera de ar sintético em um equipamento da marca NETZCH modelo STA 449 F3.

\section{Ensaio de intumescimento}

Amostras de microesferas previamente pesadas foram imersas em água destilada. Após intervalos de tempos pré-determinados, as microesferas foram retiradas do solvente e novamente pesadas. O grau de intumescimento (\%) da amostra foi calculado a partir da Equação 1, sendo $\mathrm{m}_{\mathrm{u}}$ a massa úmida após a imersão e $\mathrm{m}_{\mathrm{s}}$ a massa inicial seca do material.

$$
\text { Grau de intumescimento }(\%)=\left(\frac{m_{u}-m_{s}}{m_{s}}\right) \times 100
$$

\section{Influência do pH na taxa liberação}

A influência do $\mathrm{pH}$ na taxa de liberação foi avaliada por ensaios de condutividade iônica em diferentes meios de liberação, incluindo água e soluções tampão ( $\mathrm{pH} 4$, ácido acético; $\mathrm{pH} 8$, ácido bórico e $\mathrm{pH}$ 5,5, ácido acético, que simula o pH do solo), Tabela 2. Amostras de microesferas contendo fertilizante foram imersas em cada meio à temperatura ambiente e, após intervalos de tempos específicos, alíquotas das soluções foram coletadas e quantificadas através de um condutivímetro microprocessado GEHAKA modelo CG 2000. A concentração de íons em solução foi determinada usando uma curva de calibração do respectivo fertilizante. As análises de condutividade iônica foram realizadas em triplicata.

\section{Ensaios de liberação em solo}

Ensaios in situ foram realizados e acompanhados por medidas de condutividade elétrica utilizando a técnica da TDR (Reflectometria no Domínio do Tempo). Esta técnica permite calcular o teor de água e a condutividade elétrica do solo utilizando medições em tempo real. ${ }^{16,17}$ Para a realização do experimento, as microesferas contendo $\mathrm{KNO}_{3}$ foram acondicionadas em baldes de 7,5 $\mathrm{L}$ preenchidos com solo (latosso vermelho distrófico típico), a uma profundidade de 10 $\mathrm{cm}$ ao meio dos baldes. A Tabela 2 mostra as características químicas do solo. As sondas, que fazem a medida elétrica, foram imersas em dois pontos: uma ao meio atingindo as microesferas e duas nas laterais do balde com $5 \mathrm{~cm}$ de distância, para avaliação da liberação de fertilizantes da microesferas ao longo de todo perfil do balde, Figura 7b. Os dados foram obtidos diariamente e, sempre que necessário para manter a umidade do solo (de acordo com a capacidade de campo), realizava-se a irrigação do sistema.

\section{RESULTADOS E DISCUSSÃO}

\section{Composição química, caraterização estrutural e morfológica}

$\mathrm{O}$ fertilizante $\mathrm{KNO}_{3}$ utilizado como fonte de potássio e nitrogênio vem sendo estudado em nosso grupo como um sistema padrão para avaliar os métodos de encapsulação e de liberação em diferentes meios e análise direta no solo. ${ }^{6}$ Neste trabalho, híbridos de quitosana-argila foram preparados em sistemas de dupla camada e os materiais foram caracterizados química, estrutura e morfologicamente. A Figura 2 mostra os resultados de TG para as amostras analisadas. Observase que a degradação ocorre em três etapas principais, exceto para a amostra argila-nutriente. As etapas de perda de massa observadas para as amostras de quitosana, QAFp e QAFmcd ocorrem aproximadamente nos intervalos de 25 a $196{ }^{\circ} \mathrm{C}, 282$ a $416{ }^{\circ} \mathrm{C}$ e 516 a $910{ }^{\circ} \mathrm{C}$, os quais são atribuídos a perdas de água residual, à decomposição do polímero através de desacetilação-despolimerização, degradação dos resíduos finais do polímero e do fertilizante, ${ }^{18}$ respectivamente. As curvas TG são importantes na determinação da composição de materiais, principalmente para materiais inorgânicos baseado em análises comparativas dos componentes dos materiais. Baseado na Tabela 1, verifica-se que o teor de fertilizante se mantém constante nos materiais argila-nutriente e QAFp, mas há uma perda de fertilizante para as microesferas de camada dupla. Esta perda está relacionada com o processo de gotejamento das soluções quitosana-argila-fertilizante e à lavagem das microesferas com água até $\mathrm{pH}$ neutro. Partículas de quitosana-argila-fertilizante foram obtidas pela simples mistura

Tabela 2. Características químicas das camadas de solo de 0 a 0,2 m

\begin{tabular}{cccccccccccccccccc}
\hline $\mathrm{pH}$ & $\mathrm{MO}$ & $\mathrm{K}$ & $\mathrm{Ca}$ & $\mathrm{Mg}$ & $\mathrm{H}+\mathrm{Al}$ & $\mathrm{Al}$ & $\mathrm{SB}$ & $\mathrm{CTC}$ & $\mathrm{V}$ & $\mathrm{P}$ & $\mathrm{S}$ & $\mathrm{B}$ & $\mathrm{Cu}$ & $\mathrm{Fe}$ & $\mathrm{Mn}$ & $\mathrm{Zn}$ \\
\hline $\mathrm{CaCl}_{2}$ & $\mathrm{~g} \mathrm{dm}^{-3}$ & \multicolumn{8}{c}{$\mathrm{mmol}_{\mathrm{c}} \mathrm{dm}^{-3}$} & & & $\%$ & & & & $\mathrm{mg} \mathrm{dm}^{-3}$ & \\
\hline 5,3 & 25 & 3,7 & 35 & 17 & 33 & 1,5 & 55,6 & 88,6 & 63 & 5,3 & 62 & 0,2 & 3,7 & 11 & 42,3 & 3,0 \\
\hline
\end{tabular}

MO - Matéria orgânica; H+Al - Acidez potencial; SB - Soma de bases; CTC - Capacidade de troca catiônica; V - Saturação por bases. Dados obtidos através de análises químicas realizadas no Laboratório de Solos do Centro de Ciências Agrárias - UFSCar. 
em solução dos componentes quitosana e argila-nutriente e levados à evaporação do solvente sem prévia lavagem para neutralização do $\mathrm{pH}$. Estes dados corroboram com os resultados obtidos por absorção atômica em que aproximadamente $66 \%$ do nutriente potássio permaneceu encapsulado no material. Apesar da perda de $~ 34 \%$ do fertilizante após a obtenção das microesferas em pH neutro, ressalta-se que a preparação de dupla camada de quitosana é mais eficiente comparada à camada simples, em que os dados de absorção atômica refletem que apenas $7 \%$ do fertilizante foi encapsulado, Tabela 3.

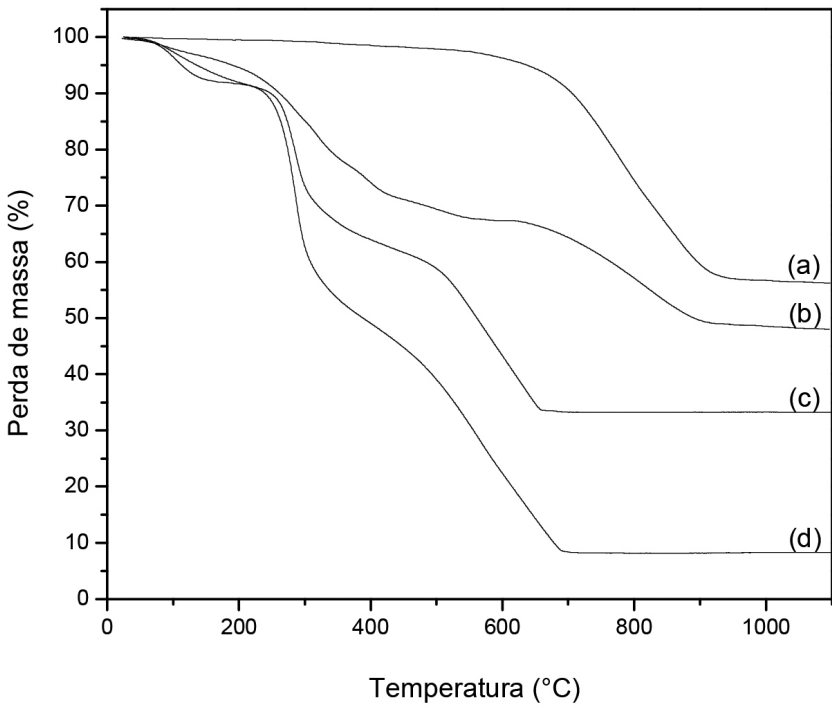

Figura 2. Curvas TG de argila-nutriente (a), QAFp (b), QAFmcd (c) e quitosana $(d)$

Tabela 3. Teor de potássio nas microesferas obtido por absorção atômica

\begin{tabular}{ccc}
\hline \multicolumn{2}{c}{ Microesferas } & Teor de K $\left(\mathrm{mg} \mathrm{L}^{-1}\right)$ \\
\hline \multirow{2}{*}{ QAFmcs } & Controle* & $39375 \pm 1803$ \\
& Microesferas & $2705 \pm 212$ \\
\hline \multirow{2}{*}{ QAFmcd } & Controle* & $35500 \pm 4010$ \\
& Microesferas & $23500 \pm 2020$ \\
\hline
\end{tabular}

*Controle - Mistura de quitosana-argila-fertilizante coletada previamente à produção das microesferas.

Comparando-se os espectros de FTIR das amostras QAFmcs e QAFmcd, Figura 3, verifica-se que as bandas associadas à quitosana permanecem inalteradas. Observa-se também uma banda larga na região de $3400 \mathrm{~cm}^{-1}$ referente ao estiramento axial de $\mathrm{O}-\mathrm{H}$ sobreposta à banda de estiramento N-H. As bandas em 1648 e $1550 \mathrm{~cm}^{-1}$ foram atribuídas ao estiramento $\mathrm{C}=\mathrm{O}$ de amida $\mathrm{I}$ e as vibrações de deformação N-H de amida II, respectivamente. Além disso, bandas de estiramento $\mathrm{C}-\mathrm{O}$ em $1100 \mathrm{~cm}^{-1}$ e de estruturas polissacarídicas na região entre 890 a $1150 \mathrm{~cm}^{-1}$ podem ser observadas. As bandas relacionadas com Si-O e Si-O-Si em 796 e 523 $\mathrm{cm}^{-1}$ estão associadas com a argila no compósito. A presença de $\mathrm{KNO}_{3}$ nos materiais é confirmada pela presença da banda em 1380 $\mathrm{cm}^{-1}$ atribuída ao estiramento simétrico $\mathrm{NO}_{3}{ }^{-}$e verifica-se que as amostras QAFp e QAFmcd apresentam maior intensidades devido à presença do fertilizante no material, corroborando os resultados de TG e absorção atômica.

Informações estruturais obtidas a partir de difratogramas de raios-X da dispersão argila-nutriente, Figura 4, indicam a presença de partículas contidas nas fases cristalinas associadas aos picos $(2 \theta=24,1$ e $26,6^{\circ}$ ) característicos do fertilizante nitrato de potássio e da argila

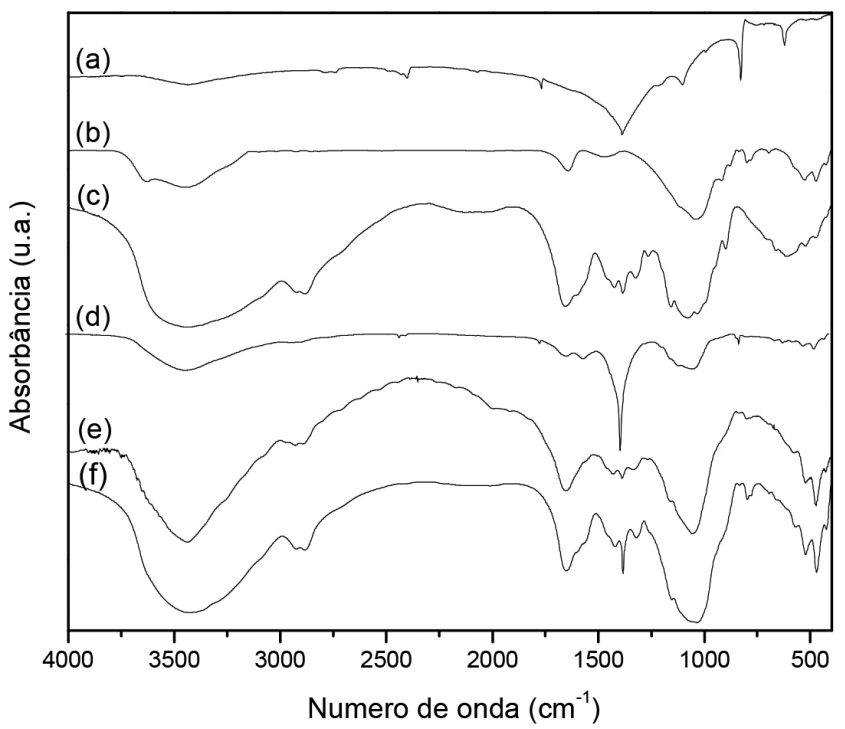

Figura 3. Espectro de FTIR do fertilizante (a), argila (b), quitosana (c), QAFp (d), QAFmcs (e) QAFmcd (f)

montmorilonita, respectivamente. No entanto, no difratograma das microesferas não são observados o aparecimento destes picos. Este comportamento pode estar relacionado ao método de preparo das microesferas por inversão de fase, cujo processo de coagulação do polímero se dá de forma rápida. Assim, o tempo necessário para a cristalização do sal pode não ter sido suficiente para gerar os cristais, evitando a organização da fase cristalina. Além disso, também é observado que o espaçamento basal da argila montmorilonita $(1,70 \mathrm{~nm})$ não está presente em nenhum dos difratogramas, que pode ser devido ao processo de esfoliação da mesma.

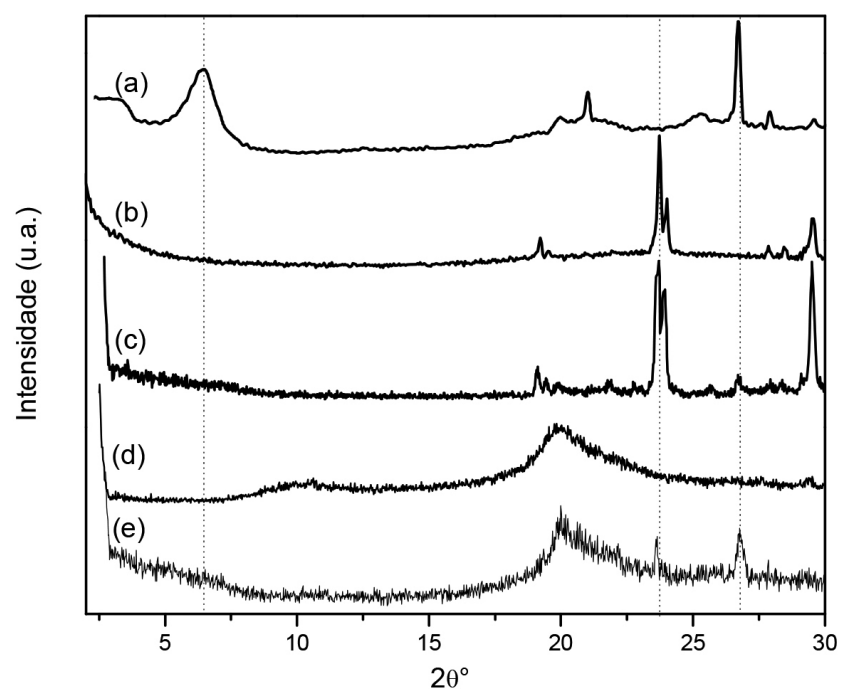

Figura 4. Difratogramas de raios- $X$ de argila montmorilonita (a), fertilizante $\mathrm{KNO}_{3}($ b), argila-nutriente (c), quitosana (d) e QAFmcd (e)

As imagens de MEV, Figura 5, revelaram que as microesferas apresentam formato de gota com pequenas deformações no ponto de interrupção e superfície sem fissuras. A fase de argila dispersa na matriz de quitosana e a região da interface descreve a compatibilização das fases, indicando boa interação matriz e cargas. As análises também apresentam o nutriente potássio disposto em várias regiões do material juntamente com a argila, nas áreas mais claras. A região de fratura evidencia uma superfície interna rugosa e porosa para o híbrido polimérico, o que proporciona uma melhor absorção 
de substâncias, corroborando com os resultados de intumescimento mostrados na Figura 6.
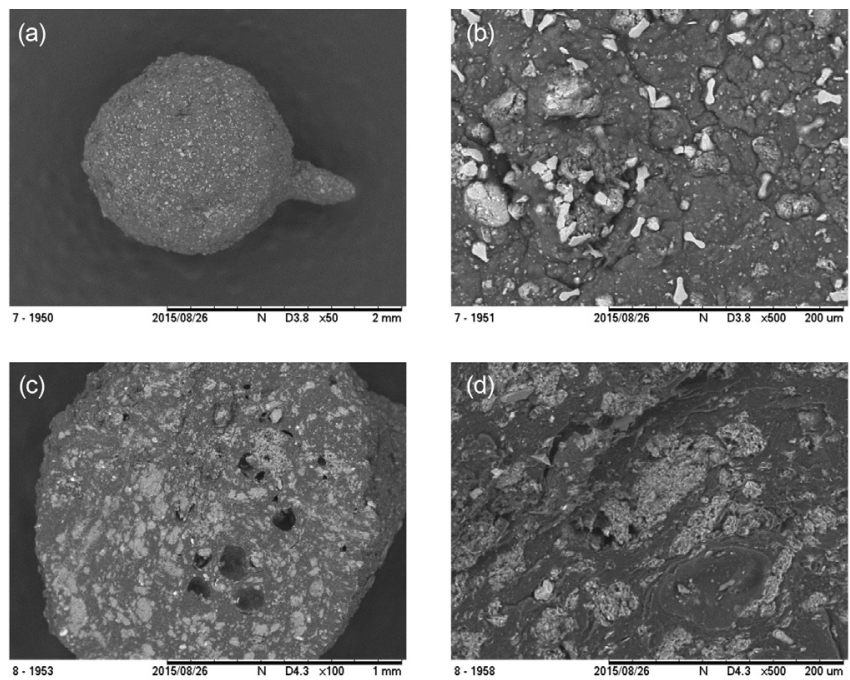

Figura 5. MEV da microesfera dupla camada da superfice $(a, b)$ e da região da fratura $(c, d)$

\section{Intumescimento e liberação em solução aquosa e em solo}

A Figura 6a mostra o grau de intumescimento das microesferas ferti-liberadoras em água destilada. Nas primeiras horas, verificou-se que as microesferas têm alta capacidade de absorver água atingindo os valores no equilíbrio de $192 \%$. Uma justificativa para este fenômeno pode estar associada à intercalação do polímero nas galerias da argila, o que pode diminuir a capacidade de ambos os materiais (argila e quitosana) incharem. Estes resultados foram consistentes com Qu e cols., ${ }^{19}$ uma vez que os aumentos de cristalinidade para compósitos proporcionam uma redução de inchaço, inibindo o efeito de difusão da água.

O perfil da curva de liberação de íons a partir das microesferas QAFmcd sugere um processo de dois estágios, Figura $6 \mathrm{~b}$. O primeiro estágio resulta no intumescimento das microesferas devido ao contato com o solvente. No segundo estágio, os íons são liberados por difusão através do polímero, exceto no $\mathrm{pH} 4$. Observou-se que para a liberação em água, os íons são liberados de forma mais vagarosa, devido ao tempo requerido para que a permeação das cargas alcance o meio a partir das cavidades internas das microesferas. Para as liberações nos pHs 4 e 5,5, pode-se observar uma velocidade de liberação mais rápida dos íons encapsulados em relação aos demais meios. No entanto, notou-se que as amostras de microesferas são dissolvidas em $\mathrm{pH} 4$ por conta da acidez do próprio meio. Assim, isto pode ter contribuído para que os íons contidos e/ou depositados na matriz de quitosana das microesferas alcançassem o meio em menor tempo. Para a liberação no $\mathrm{pH} 8$, verificou-se que a liberação segue o processo de dois estágios citado anteriormente e seu perfil aproxima-se do comportamento observado em água, como mostrado na Figura 6 b.

A técnica de TDR foi usada para avaliar a liberação do fertilizante por 60 dias. O TDR avalia as alterações na condutividade do solo, no entanto, pode-se correlacionar a condutividade iônica com a concentração de íons utilizando a Equação $2,{ }^{20}$ sendo $\mathrm{C}$ a concentração de nitrato de potássio $\left(\mathrm{mmol} \mathrm{L}^{-1}\right)$ e $\mathrm{CE}_{\mathrm{S}}$ a condutividade elétrica da solução $\left(\mathrm{dS} \mathrm{m} \mathrm{m}^{-1}\right)$.

$$
\mathrm{C}=\left(\frac{\mathrm{CE}_{\mathrm{s}}}{0,173}\right)^{\frac{1}{0,916}}
$$
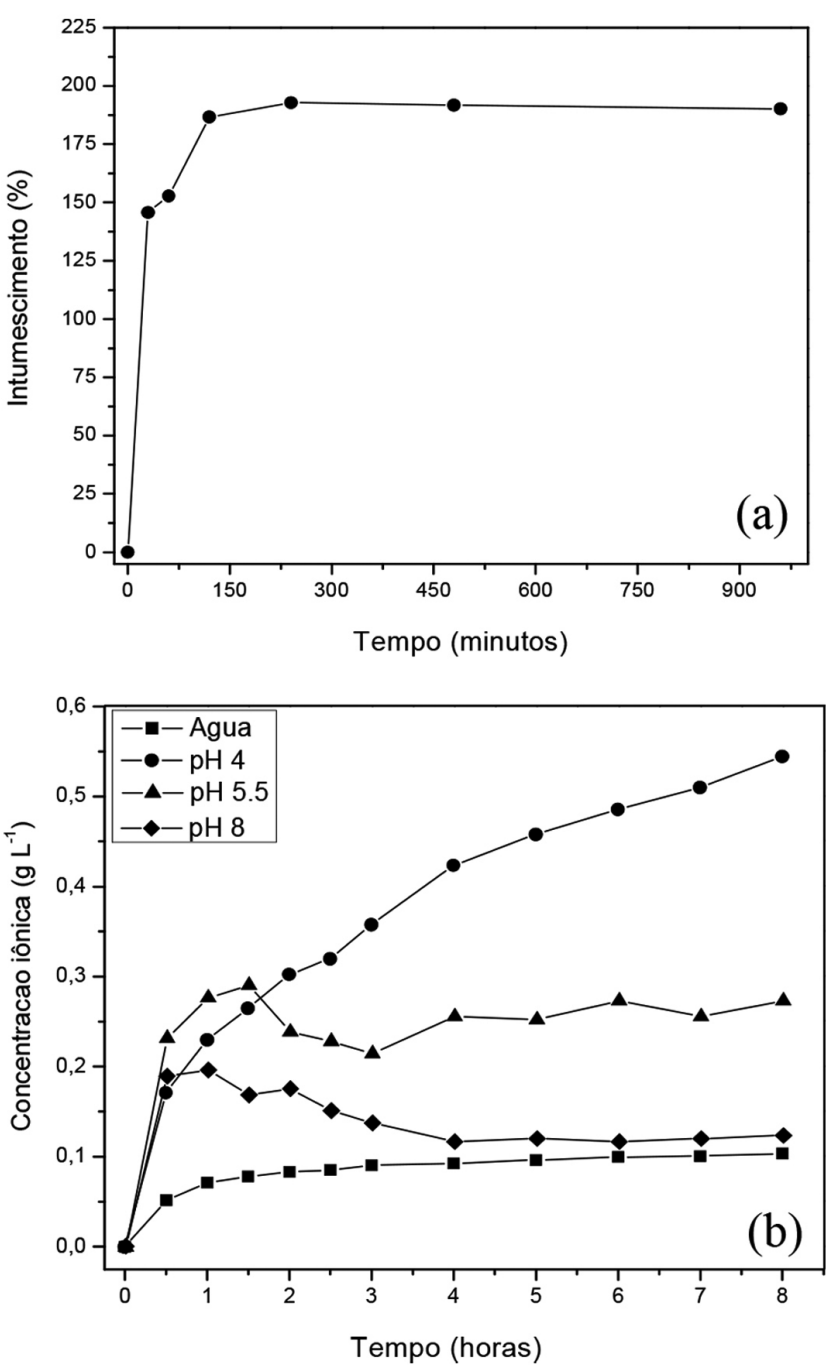

Figura 6. Grau de intumescimento em água (a) e taxas de liberação de íons em diferentes pHs (b) das microesferas de camada dupla

A liberação de fertilizante foi estimada com base na condutividade elétrica das sondas central e lateral, Figura 7, e os dados foram relacionados com a concentração de íons potássio no solo. De acordo com o perfil de liberação de potássio das sondas centrais, a maior liberação de fertilizante ocorre durante os primeiros dias, atingindo valores próximos de $0,706 \mathrm{~g} \mathrm{~L}^{-1}$. Esta liberação inicial representa a quantidade de fertilizante depositada sobre as superfícies das microesferas (as sondas centrais estão em contato com o material). Ao longo do experimento, a concentração de íons potássio diminui até um valor constante ser atingido. Com isso, os fertilizantes contidos no interior das microesferas permeiam para solo. Este estágio de liberação se apoia na dinâmica de íons em solo devido à concentração de $\mathrm{K}^{+}$aumentar nas sondas laterais com o tempo.

\section{CONCLUSÕES}

O presente estudo demonstra um processo fácil para a síntese de um material com liberação controlada de fertilizantes combinado com a determinação direta dos nutrientes em água e solo. O método de preparo empregado mostrou-se promissor para a produção de microesferas e encapsulamento do fertilizante nitrato de potássio. Análises estruturais confirmaram a presença do nutriente $\mathrm{KNO}_{3}$ nas microesferas ferti-liberadoras, evidenciando a capacidade do híbrido polimérico em encapsular o fertilizante químico. Resultados de DRX 


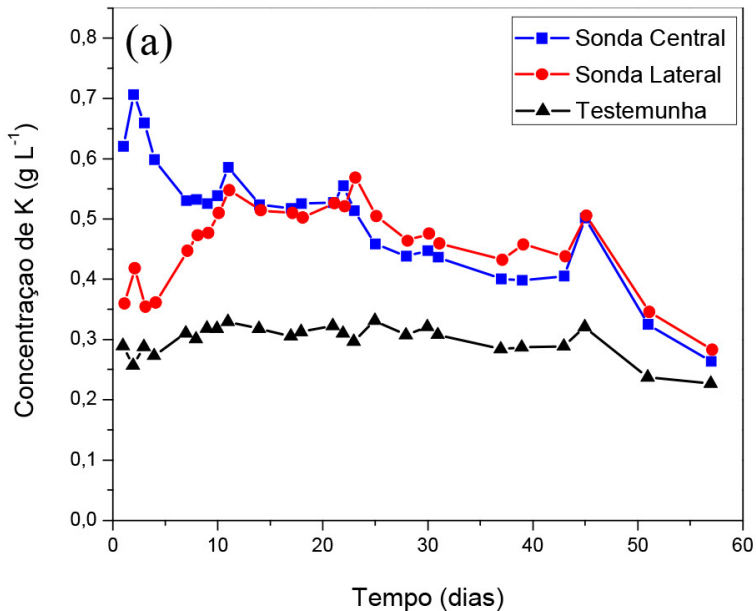

Figura 7. Ensaio de liberação in situ de nutrientes (a), sondas TDR (b)

indicaram a ocorrência da formação de um sistema amorfo, o que do ponto de vista tecnológico é interessante, pois a capacidade do híbrido em absorver moléculas é favorecida com a diminuição do grau de cristalinidade de sua estrutura. Ensaios de intumescimento constataram que as microesferas possuem alta capacidade de absorver água, corroborando com os resultados de DRX. O perfil de liberação comprovou que os íons são liberados das microesferas para o meio de forma lenta e continua por difusão através do polímero. Verificou-se que fatores como pH impõe uma modificação ao perfil de liberação. A técnica TDR permitiu a determinação do perfil real de liberação de nutrientes no solo.

\section{AGRADECIMENTOS}

À FAPESP (proc. 2014/06566-9 e 2014/09045-0) e à Bentonit União pela concessão da Argila Montmorilonita.

\section{REFERENCIAS}

1. http://www.ibram.org.br/sites/1300/1382/00000978.pdf, acessada em março 2016.

2. Welter, M. K.; Melo, V. F.; Bruckner, C. H.; de Góes, H. T.; Chagas, E. A.; Uchôa, S. C. P.; Rev. Bras. Frutic. 2011, 33, 922.

3. http://www.anda.org.br/boletins/fertilizantes_meio_ambiente.pdf, acessada em março 2016.

4. Chen, L.; Xie, Z.; Zhuang, X.; Chen, X.; Jing, X.; Carbohydr. Polym. 2008, 72, 342 .

5. Ghormade, V.; Deshpande, M. V.; Paknikar, K. M.; Biotechnol. Adv. 2011, 29, 792

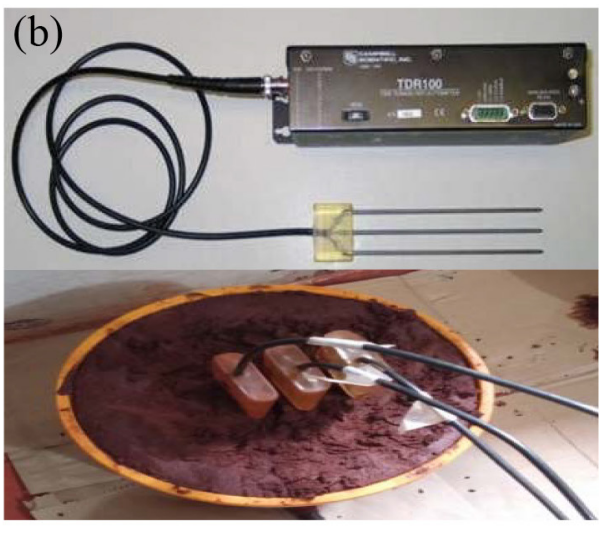

6. Santos, B. R.; Bacalhau, F. B.; Pereira, T. S.; Souza, C. F.; Faez, R.; Carbohydr. Polym. 2015, 127, 340.

7. Vandana, G.; Mukund, V. D.; Kishore, M. P.; Biotechnol. Adv. 2011, 29, 792.

8. Wu, L.; Liu, M.; Carbohydr. Polym. 2008, 72, 240.

9. Torres, M. A.; Vieira, R. S.; Beppu, M. M.; Arruda, E. J.; Santana, C. C.; Mat. Res. 2007, 10, 347.

10. Dias, F. S.; Queiroz, D. C.; Nascimento, R. F.; Lima, M. B.; Quim. Nova 2008, 31, 160 .

11. Kumar, M. N. V. R.; React. Funct. Polym. 2000, 46, 27.

12. Azevedo, V. V. C.; Chaves, S. A.; Bezerra, D. C.; Fook, M. V. L.; Costa, A. C. F.; Revista Eletrônica de Materiais e Processos 2007, 2.3, 27.

13. Park, D.-H.; Hwang, S.-J.; Oh, J.-M.; Yang, J-H.; Choy, J.-H.; Prog. Polym. Sci. 2013, 38, 1442.

14. Torres, M. A.; Viera, R. S.; Beppu, M. M.; Santana, C. C.; Polímeros 2005, 15, 306.

15. Kashyap, P. L.; Xiang, X.; Heiden, P.; Int. J. Biol. Macromol. 2015, 77, 36.

16. Noborio, K.; Computers and Electronics in Agriculture 2001, 31, 213.

17. Conciani, W.; Herrmann, P. S. P.; Machado, S. L.; Soares, M. M.; Solos e Rochas 1996, 19, 189.

18. Wang, S. F.; Shen, L.; Tong, Y. J.; Chen, L.; Phang, I. Y.; Lim, P. Q.; Liu, T. X.; Polym. Degrad. Stabil. 2005, 90, 123.

19. Qu, X.; Wirsén, A.; Albertsson, A. C.; Polymer 2000, 41, 4589.

20. Souza, C. F.; Folegatti, M. V.; Matsura, E. E.; Or, D.; Eng. Agric. 2006 , $26,282$. 